\title{
Citrobacter diversus brain abscess: case reports and molecular epidemiology
}

\author{
M. G. MORGAN, C. STUART*, A. T. LEANORD, M. ENRIGHT and G. F. COLE* \\ Department of Medical Microbiology, University of Aberdeen and Department of Paediatrics, The Royal Aberdeen \\ Children's Hospital, Foresterhill, Aberdeen AB9 220
}

\begin{abstract}
Summary. Citrobacter diversus brain abscess occurred in two infants in Aberdeen, 5 months apart. These are the first reported cases of this condition in the UK since 1976. Restriction endonuclease analysis with SacI enzyme showed blood and CSF isolates from both patients to be identical and different from 10 other clinical isolates of $C$. diversus and one $C$. amalonaticus strain. Furthermore, isolates of $C$. diversus from patients belonged to biotype "d" whereas control isolates were of biotypes " $a$ " or " $e$ ". Because both infants attended the same central and peripheral maternity units, this raised suspicions of long term contamination of the hospital environment by this organism. Sodium dodecyl sulphate-polyacrylamide gel electrophoresis (SDS-PAGE) patterns of whole-cell proteins and immunoblotting with normal human serum were remarkably homogeneous for all $13 C$. diversus strains and thus were not useful for typing. However, the only $C$. amalonaticus strain was clearly differentiated from $C$. diversus strains by SDS-PAGE. Management of the infants included multiple intravenous antibiotic therapy for 4-6 weeks and repeated computerised tomography (CT) scanning and drainage of the abscess cavity. Both children survived albeit with some minor degree of brain damage.
\end{abstract}

\section{Introduction}

Citrobacter diversus (syn. C. koseri or Levinea malonatica) is now considered to be the organism most frequently associated with neonatal brain abscess. ${ }^{1}$ Other members of the family Enterobacteriaceae, e.g., Escherichia coli, are more commonly associated with neonatal meningitis. However, $C$. diversus meningitis is very often complicated by brain abscess formation $(77 \%))^{2,3}$ Furthermore, the mortality rate is high (34\%) and the majority of children who recover suffer varying degrees of brain damage ${ }^{3}<5 \%$ of infants make a complete recovery. Since the first reports of nursery outbreaks of $C$. diversus meningitis from England in $1973,{ }^{4,5}$ several sporadic cases ${ }^{1,6,7}$ as well as small outbreaks ${ }^{8-11}$ have been reported from the USA. The last report from the UK was that of Ribeiro et al. ${ }^{12}$ who described an outbreak of neonatal $C$. diversus meningitis in a Manchester hospital in 1976.

The epidemiology of $C$. diversus neonatal meningitis remains unclear, largely because a satisfactory typing system does not exist. Biotyping, ${ }^{8-10}$ antibiograms 9,10 and serotyping $8,10,11$ have been used to characterise strains. However, organisms associated with out-

Received 4 April 1991; accepted 25 June 1991. breaks of meningitis belong to several biotypes and serotypes and correlation between these various markers is poor. ${ }^{11} \mathrm{Kline} e t$ al. ${ }^{13}$ have found that $C$. diversus strains causing neonatal meningitis are more likely than others to possess a 32-K da outer-membrane protein (OMP) when examined by sodium dodecyl sulphate-polyacrylamide gel electrophoresis (SDSPAGE). In a further study, ${ }^{14}$ strains possessing the 32-Kda OMP were found to be genetically heterogeneous by multilocus enzyme electrophoresis. Restriction endonuclease analysis (REA) with multiple enzymes has been used 'in the investigation of meningitis outbreaks in three Maryland hospitals. ${ }^{11}$ In two of these hospitals, identical $C$. diversus strains were isolated from affected infants, healthy neonates and nursery personnel. Different $C$. diversus strains were also isolated in all three hospitals.

We report here the first two cases of $C$. diversus brain abscess recorded in the UK since 1976. Three isolates of $C$. diversus from CSF and blood of these patients were compared to 11 other clinical isolates with respect to biotype, antibiogram, SDS-PAGE of whole-cell proteins (WCP) and immunoblotting with normal human serum (NHS); REA was also performed on all strains. SDS-PAGE of WCP and immunoblotting have not previously been reported for $C$. diversus strains associated with meningitis and brain abscess. 


\section{Case reports}

\section{Case 1}

A female infant was delivered at term by elective caesarean section because of cephalopelvic disproportion. She appeared well at birth, was moved on the second day from the central maternity hospital to a peripheral unit, and was discharged home well on day 10. She was admitted to the Children's Hospital $24 \mathrm{~h}$ later because she was febrile and reluctant to feed; examination revealed an ill, irritable, pale infant but no specific abnormal findings. A full infection screen was performed and the cerebrospinal fluid (CSF) was found to be turbid with a white cell count of $1.97 \times$ $10^{9} / \mathrm{L}, 94 \%$ of which were polymorphonuclear leucocytes. Gram-negative bacilli were seen in the gramstained film. Treatment was started with intravenous (i.v.) cefotaxime and gentamicin, and phenobarbitone was given because of the baby's extreme irritability. Ultrasound scan of her head $24 \mathrm{~h}$ after admission was reported as normal.No organisms were seen in CSF taken $24 \mathrm{~h}$ and $48 \mathrm{~h}$ after admission and the samples were sterile. At this point, the organism in the initial CSF specimen was identified as $C$. diversus whereupon chloramphenicol was added to the antibiotic regimen. The same species was identified in blood cultures taken on admission.

CT scan 1 week after admission demonstrated an abscess cavity $3 \mathrm{~cm}$ in diameter in the right frontal lobe, and several other suspicious areas of oedema. Frequent imaging by both ultrasound and CT scan demonstrated the evolution of two further abscess cavities, one in the left frontal lobe and the other in the left posterior parietal region. These cystic cavities were drained on several occasions and gentamicin was instilled. Very scanty gram-negative organisms were seen in the fluid on the first occasion, but there was no growth on culture. Progressive ventricular dilatation was controlled after 3 weeks by the insertion of a ventriculo-peritoneal (VP) shunt. The post-operative course was complicated by a cerebral haemorrhage in the region of the third ventricle and the infant developed seizures which were difficult to control. Intravenous antibiotics were continued for 6 weeks, although chloramphenicol had been stopped after 3 weeks. The baby made a slow recovery and at the time of discharge, 7 weeks after admission, she was markedly hypotonic, had poor visual responsiveness and her visual evoked responses (VERs) were abnormal.

At the age of 1 year, the child had nystagmus affecting her right eye only but her visual responsiveness and VERs were markedly improved. Her seizures were well controlled by anticonvulsant therapy. She was pulling to stand and cruising around the furniture; fine motor skills were generally a little delayed, but on the whole her progress was pleasing. A CT scan at that time showed a persisting right frontal cavity but the other cavities had completely resolved.

\section{Case 2}

Five months after Case 1, a female infant was delivered at term by emergency caesarean section because of failure of labour to progress. She was delivered in the same central maternity unit, transferred to the same peripheral unit after $48 \mathrm{~h}$, and was discharged home well on day 10 . She was admitted to the Children's Hospital at the age of 5 weeks with a 4day history of vomiting, lethargy, reluctance to feed and constipation; on examination she appeared unwell but was afebrile. Her fontanelle was tense and there was marked splaying of the cranial sutures. Lumbar puncture was considered inadvisable and she was given intravenous ampicillin and chloramphenicol empirically. A CT scan demonstrated a $5-\mathrm{cm}$ abscess cavity in the right frontal lobe. This cavity was aspirated and $C$. diversus was isolated from the fluid. Blood and stool culture results were negative. When the sensitivity pattern of the organism was known, the antibiotic regimen was changed to i.v. cefotaxime and gentamicin which were continued for 6 weeks. Intracranial events were monitored by head circumference measurements and frequent imaging by both CT and ultrasound scan. The abscess cavity was aspirated and gentamicin was instilled on a further six occasions. The infant developed seizures and a progressive communicating hydrocephalus which was controlled by VP shunt 5 weeks after the onset of her illness. Her post-operative course was uneventful and she was discharged 8 weeks after admission. At this time she was generally hypotonic, visually unresponsive and her VERs were of reduced amplitude and increased latency.

At 1 year old, the seizures were well controlled by anticonvulsant therapy and she was visually and socially responsive. Repeat VERs were much improved, although not normal. Her tone was normal and development seemed satisfactory although her fine motor skills were mildly delayed. A CT scan showed a large area of scarring in the left frontal region with some dilatation of the aqueduct and fourth ventricle.

\section{Materials and methods}

\section{Samples}

Three isolates of $C$. diversus (A-C) were obtained from CSF and blood of the two cases. Eleven other clinical isolates (D-N) were randomly selected from clinical material other than CSF or blood (table). These latter isolates were identified by the API 20E system (API Laboratories, Basingstoke, Hants) as $C$. diversus/amalonaticus and were not chosen on the basis of clinical significance. Swabs were also obtained from the wet environment of the labour ward, and the central and peripheral maternity units 9 months after the second case to determine whether there was contamination with $C$. diversus. 


\section{Biotyping and antibiograms}

The API 20E result does not distinguish $C$. diversus from the closely related species $C$. amalonaticus. To make this distinction, extra biochemical tests were employed. Isolates classified as $C$. diversus gave positive results in tests for malonate utilisation, adonitol and D-arabitol fermentation whereas $C$. amalonaticus isolates gave negative results. Biotyping of $C$. diversus isolates was based on fermentation tests with dulcitol, sucrose, D-sorbose and L-rhamnose. ${ }^{15}$ Antibiotic sensitivity tests were performed by a modification of the Stokes's disk diffusion method: with a rotary plater, the test organism was inoculated on the inside and the control organism (E. coli NCTC 10418 ) on the outside of DST (Oxoid) agar plates. Antibiotics tested with Oxoid sensitivity disks were ampicillin $(10 \mu \mathrm{g})$, co-amoxyclav $(30 \mu \mathrm{g})$, piperacillin $(75 \mu \mathrm{g})$, cefuroxime $(30 \mu \mathrm{g})$, cefotaxime $(30 \mu \mathrm{g})$, ceftazidime $(30 \mu \mathrm{g})$, trimethoprim $(2.5 \mu \mathrm{g})$, gentamicin $(10 \mu \mathrm{g})$, netilmicin $(30 \mu \mathrm{g})$, amikacin $(30 \mu \mathrm{g})$, ciprofloxacin $(1 \mu \mathrm{g})$, imipenem $(10 \mu \mathrm{g})$ and chloramphenicol $(30 \mu \mathrm{g})$.

\section{SDS-PAGE and immunoblotting}

These were performed broadly in accordance with the method of Maggs and Pennington ${ }^{16}$ except as detailed below. All isolates were cultured on nutrient agar for $24 \mathrm{~h}$ at $37^{\circ} \mathrm{C}$, and then harvested, washed, and resuspended in sterile saline before sonication, with cooling in an ice bath, for $2 \mathrm{~min}$. Sonicated extracts were stored at $-70^{\circ} \mathrm{C}$ until use. For SDSPAGE and immunoblotting, sonicated extracts were mixed with three volumes of $0.01 \mathrm{M}$ Tris- $\mathrm{HCl}$ buffer, pH 6.8, containing SDS $4.4 \% \mathrm{w} / \mathrm{v}$, glycerol $20 \% \mathrm{v} / \mathrm{v}$, 2-mercaptoethanol $20 \% \mathrm{v} / \mathrm{v}$ and bromophenol blue $0.001 \% \mathrm{w} / \mathrm{v}$, and heated for $5 \mathrm{~min}$ in a boiling water bath. Samples were then centrifuged for $5 \mathrm{~min}$ at $11500 \mathrm{~g}$ in a microcentrifuge, electrophoresed on an acrylamide $10 \%$ separating gel with a $4 \%$ stacking gel and stained with Coomassie Brilliant Blue R.

Immunoblotting was performed by transferring by overnight electrophoresis material from acrylamide gels to nitrocellulose membranes (Hybond-C, Amersham, Bucks). The membranes were then incubated for $1 \mathrm{~h}$ at $37^{\circ} \mathrm{C}$ in a blocking buffer of $0.1 \mathrm{M}$ phosphate-

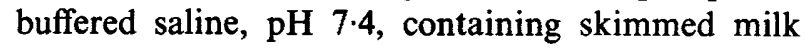
powder (Oxoid) $3 \% \mathrm{w} / \mathrm{v}$. Pooled normal human serum (Blood Transfusion Service, Aberdeen Royal Infirmary), diluted 100 -fold in blocking buffer, was used as the primary antibody and peroxidase-labelled antihuman IgG (SAPU, Law Hospital, Carluke), diluted 100-fold in blocking buffer, was used to detect antibody binding. Banding patterns obtained for different isolates were compared visually.

\section{Restriction endonuclease analysis}

DNA was extracted by a procedure based on that of Bjorvatn et al. ${ }^{17}$ Total yields, measured at $260 \mathrm{~nm}$, were $0.5-4 \mathrm{mg} / \mathrm{ml}$. Eleven restriction enzymes (ApaI, AluI, BamHI, DraII, EcoRV, HaeIII, KpnI, PstI, SacI, SaII and TaqI) were used to establish the most discriminatory banding patterns. SacI gave the most useful banding pattern and was subsequently used for all further digests. DNA ( $5 \mu \mathrm{g})$ was digested overnight with 5 units of restriction endonuclease and electrophoresed in agarose $0.8 \%$ at $5 \mathrm{~V} / \mathrm{cm}$. DNA banding patterns were visualised under UV light after staining with ethidum bromide.

\section{Results}

\section{Biotyping and antibiograms}

The API profiles and biotypes of the 14 isolates are outlined in the table. One isolate $(\mathrm{J})$ gave negative results in tests for utilisation of malonate and citrate

Table . Citrobacter strains and biotypes

\begin{tabular}{|c|c|c|c|c|c|c|c|}
\hline \multirow{2}{*}{$\begin{array}{c}\text { Isolate } \\
\text { designation }\end{array}$} & \multirow{2}{*}{ Source } & \multirow{2}{*}{ API profile } & \multicolumn{4}{|c|}{ Fermentation of } & \multirow{2}{*}{ Biotype } \\
\hline & & & dulcitol & sucrose & D-sorbose & L-rhamnose & \\
\hline A & Blood (case 1) & 1344533 & + & + & + & + & $\mathrm{d}$ \\
\hline B & CSF (case 1) & 1344533 & + & + & + & + & $\mathrm{d}$ \\
\hline $\mathrm{C}$ & CSF (case 2) & 1344533 & + & + & + & + & $\mathrm{d}$ \\
\hline $\mathrm{D}$ & Stool & 1344513 & - & - & + & + & $\mathrm{a}$ \\
\hline $\mathrm{E}$ & $\mathrm{CSU}$ & 1344513 & - & - & + & + & $a$ \\
\hline $\mathrm{F}$ & Sputum & 3344533 & - & + & + & + & e \\
\hline $\mathrm{G}$ & Sputum & 3344513 & - & - & + & + & $a$ \\
\hline $\mathbf{H}$ & CSU & 3344513 & - & - & + & + & a \\
\hline I & CSU & 3344513 & - & - & + & + & $\mathbf{a}$ \\
\hline $\mathbf{J}$ & MSU & 3344513 & - & - & + & + & C. amalonaticus \\
\hline $\mathbf{K}$ & MSU & 1344513 & - & - & + & + & a \\
\hline $\mathrm{L}$ & MSU & 3344512 & - & - & + & + & a \\
\hline$\vec{M}$ & Burn graft & 3344513 & - & - & + & + & a \\
\hline $\mathbf{N}$ & Breast ulcer & 3344513 & - & - & + & + & $\mathrm{a}$ \\
\hline
\end{tabular}

CSF, cerebrospinal fluid; CSU, catheter specimen of urine; MSU, midstream specimen of urine. 


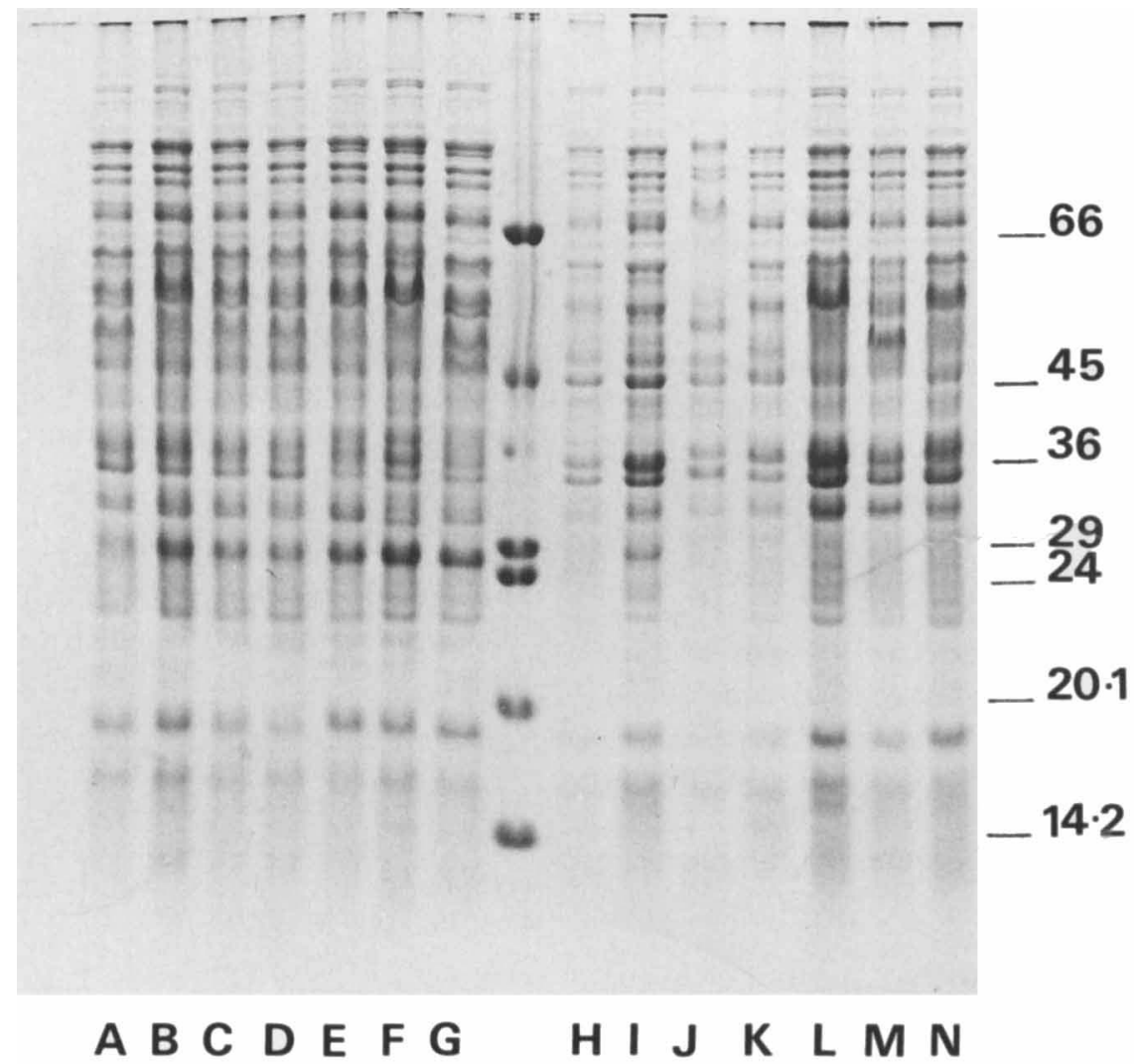

Fig. 1. SDS-PAGE of WCPs from 14 Citrobacter isolates. Lane A, case 1 blood isolate; B, case 1 CSF isolate; C, case 2 CSF isolate; D-I and $\mathbf{K}-\mathbf{N}$, control $C$. diversus isolates; $\mathbf{J}, C$. amalonaticus isolate; mol.-wt markers (Kda) are between lanes $\mathbf{G}$ and $\mathbf{H}$ and listed.

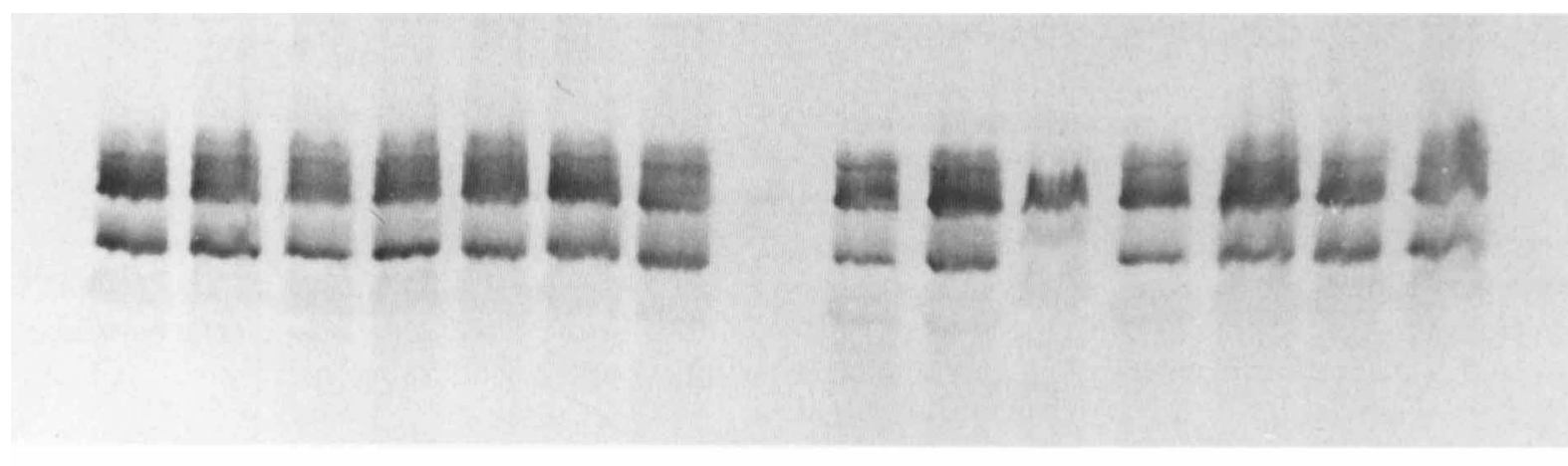

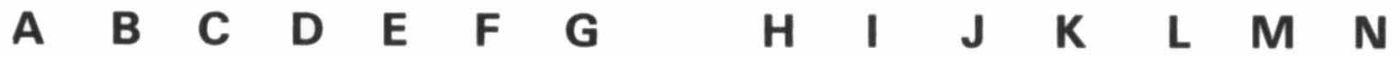

Fig. 2. Immunoblot of 14 Citrobacter isolates with normal human serum. Lane designations correspond to those in fig. 1 and the table.

and for fermentation of $\mathrm{D}$-arabitol and adonitol; therefore it was identified as $C$. amalonaticus. Of the $13 C$. diversus strains, the three CSF and blood isolates from our patients (isolates A-C) were biotype "d". The remaining isolates were biotype "a" with the exception of isolate $F$ which was biotype "e". All isolates were resistant to ampicillin and sensitive to the other antibiotics tested. Environmental sampling yielded no $C$. diversus isolates.

\section{SDS-PAGE and immunoblotting}

SDS-PAGE profiles of whole cell proteins showed remarkable homogeneity among $C$. diversus isolates and there were no discernible differences between abscess-causing isolates and others. However, the only C. amalonaticus isolate (J) was clearly different (fig. 1). Immunoblotting with normal human serum revealed two prominent bands of high mol. wt ( $>66 \mathrm{Kda}$ ) but again provided no discrimination between $C$. diversus isolates. However, the $C$. amalonaticus strain was different, having only one prominent, high mol.-wt band (fig. 2).

\section{Restriction endonuclease analysis}

Fig. 3 shows the REA "fingerprints" of isolates A$\mathrm{N}$. Isolates A, B and C gave indistinguishable banding 


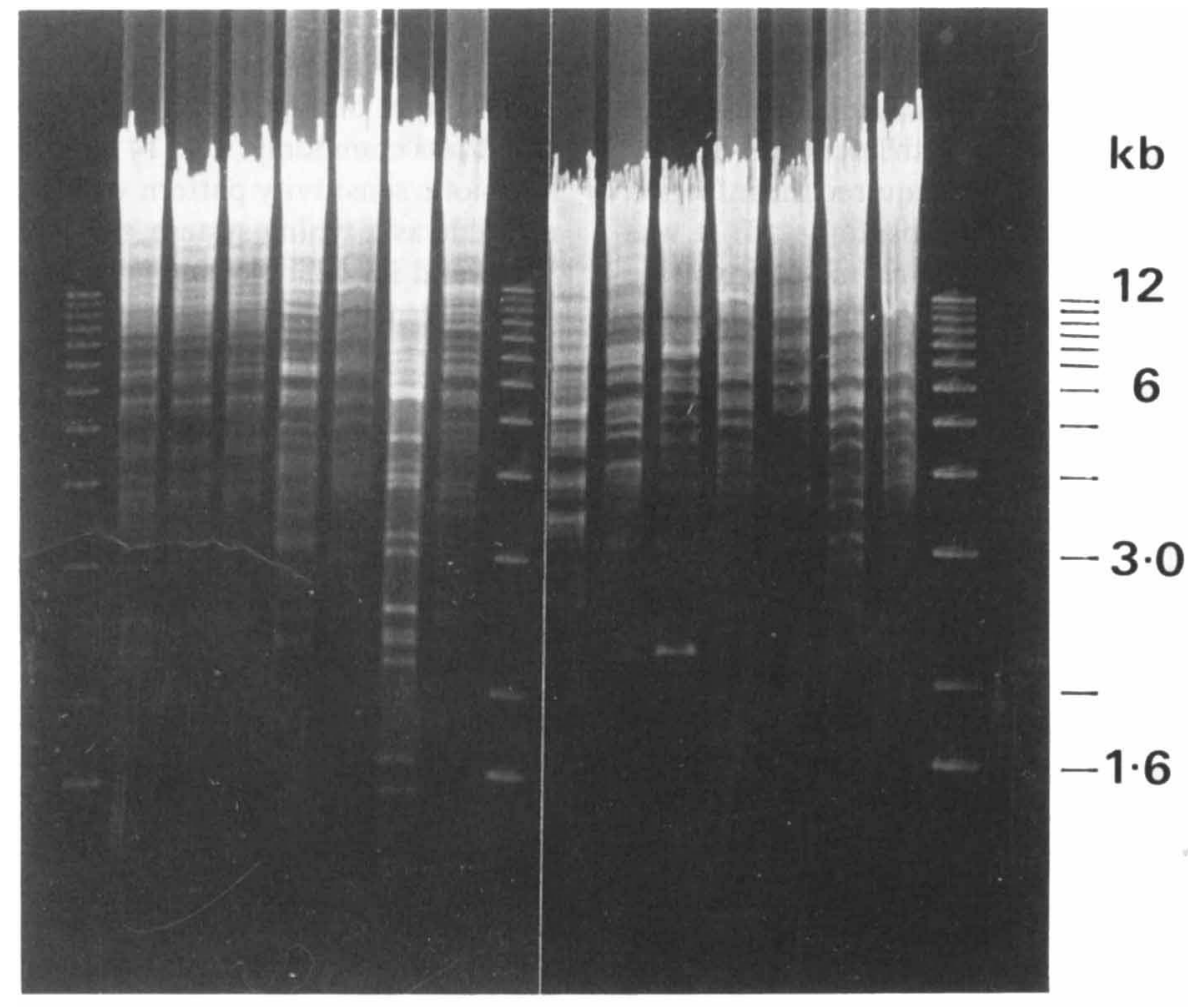

A BCDEFG H I J K L M N

Fig. 3. Agarose gel electrophoresis of SacI digests of whole-cell DNA extracted from 14 Citrobacter isolates. Lanes 1, 9 and 17, 1-kb markers; 2-8 and 10-16, Citrobacter isolates $A-G$ and $H-N$ respectively, designated as in fig. 1 and the table.

patterns. Isolates $\mathrm{D}-\mathrm{N}$ gave unique banding patterns that were easily distinguishable from one another and from those of isolates A-C.

\section{Discussion}

Organisms belonging to the genus Citrobacter are widespread in the environment, being found in soil and water. $C$. freundii, the type species, is commonly carried in the large intestine and may be confused biochemically with Salmonella spp. (many strains are lactose non-fermenters and $\mathrm{H}_{2} \mathrm{~S}$ positive). On the other hand, the carriage rate of $C$. diversus in the intestine is thought to be low $^{18}$ except during nursery outbreaks when it may be as high as $79 \%^{8,12}$ Citrobacter spp. have been associated with significant nosocomial infection-including urinary tract infection, especially in catheterised patients, respiratory tract infections, bacteraemia and endocarditis, especially in elderly or debilitated patients. Most clinical isolates represent secondary infection or asymptomatic colonisation. However, $C$. diversus is now recognised as an important cause of neonatal meningitis ${ }^{2}$ and the commonest cause of brain abscess in neonates. ${ }^{1}$ Most affected infants are under 6 weeks of age and no cases have been recorded beyond 8 weeks. This suggests that host susceptibility is an important predisposing factor.

The pathogenesis of $C$. diversus meningitis and brain abscess remains unclear. Studies in the infant rat $^{19}$ have shown that the infection is haematogeneous in origin. Leptomeningitis is followed by ventriculitis and direct extension of organisms into the adjacent brain tissue. C. diversus strains isolated from CSF did not differ from those isolated elsewhere with respect to pilation, haemolysin production and resistance to the killing effect of serum..$^{13}$ One study demonstrated that $C$. diversus strains causing neonatal meningitis were more likely than others to possess a $32-\mathrm{Kda}$ OMP. ${ }^{13}$ However, a further study by the same group ${ }^{20}$ failed to "shed new light" on this association.

Our two cases had several features in common. They came from the same small town and shared the same General Practitioner and Health Visitor. Moreover, both babies were delivered at term by lower segment caesarian section and both were in the same central and peripheral maternity units in the immediate postnatal period. Although nearly 5 months elapsed between the first and second case, environmental transmission could not be excluded. Other workers have shown that $C$. diversus is capable of prolonged survival (up to 4 years) in the hospital environment, ${ }^{3}$ leading to protracted nursery outbreaks of meningitis and brain abscess, albeit with a low case:carrier ratio of $4 \%{ }^{8,12}$ A faecal reservoir of infection ${ }^{8}$ and transmission via hands ${ }^{9}$ of nursery personnel have been implicated in outbreaks. Vertical transmission of $C$. diversus has also been described, ${ }^{7}$ the organism being carried in the intestine and transmitted to the 
infant during labour or in the immediate post-natal period. Considering the early onset of brain abscess formation in case 1 ( 9 days), vertical transmission is a real possibility, whereas case 2 , with later onset disease (5 weeks), is more likely to have acquired the infection from the environment or from hospital staff. It was considered inadvisable to attempt to demonstrate faecal carriage of $C$. diversus in the mother because such knowledge might have proved distressing to already stressed parents. Furthermore, environmental contamination, staff carriage and infant colonisation with $C$. diversus were not investigated at the time because cross contamination was not suspected in view of the long interval between cases.

The first indication that cross contamination might have occurred came 9 months after the second case when REA demonstrated the identity of $C$. diversus isolates from the two cases. Environmental sampling at this time did not reveal any $C$. diversus contamination and routine testing revealed no further cases of $C$. diversus colonisation or infection amongst our neonates. The isolates from cases also differed by REA from the other 10 clinical isolates of $C$. diversus and the one $C$. amalonaticus strain, and the abscess-causing islates $(A-C)$ were biotype " $d$ " whereas other isolates were generally of biotype " $a$ " with one strain of biotype "e". Other workers have also found biotype
" $d$ " to be predominant among abscess-causing strains. ${ }^{3}$ Brain abscess due to strains of biotype "a"3 and the rare biotype " $\mathrm{e} "{ }^{10}$ have also been described, albeit less commonly. The 14 strains did not differ in antibiotic sensitivity pattern which was, therefore, of no value as a typing system, nor were SDS-PAGE of WCP and immunoblotting with NHS, both of which showed remarkable homogeneity among $C$. diversus strains. However, distinct banding patterns were obtained with the one $C$. amalonaticus strain by SDSPAGE and this method may be useful for interspecies differentiation.

C. diversus may cause protracted outbreaks of neonatal meningitis and brain abscess involving a small number of cases over a long period of time. ${ }^{21}$ This may be due to its propensity for long term colonisation of the hospital environment or of hospital staff. REA is a useful epidemiological tool in the management of such outbreaks. Prolonged intravenous antibiotics combined with repeated CT scanning and drainage of the abscess cavities are used in the management of individual cases.

We are indebted to Professor T. H. Pennington for his helpful advice, to Mrs Betty Smith for typing the manuscript and to G. Hepburn and C. Grant for providing control strains. A. Leanord is a member of the British Antarctic Survey Medical Unit, RGIT Survival Centre Ltd, Aberdeen.

\section{References}

1. Curless RG. Neonatal intra-cranial brain abscess: two cases caused by Citrobacter and a literature review. Ann Neurol 1980; 8: 269-272.

2. McCracken GH, Threlkeld N, Mize S et al. Moxalactam therapy for neonatal meningitis due to gram-negative enteric bacilli : a prospective controlled evaluation. JAMA $1984 ; 252: 1427-1432$

3. Graham DR, Band JD. Citrobacter diversus brain abscess and meningitis in neonates. JAMA 1981 ; 245: 1923-1925.

4. Gwynn CM, George RH. Neonatal Citrobacter meningitis. Arch Dis Child 1973; 48: 455-458.

5. Gross RJ, Rowe B, Easton JA. Neonatal meningitis caused by Citrobacter koseri. J Clin Pathol 1973; 26: 138-139.

6 .Tamborlane WV, Soto EV. Citrobacter diversus meningitis: a case report. Pediatrics $1975 ;$ 55: 739-741.

7. Finn A, Talbot GH, Anday E, Skros M, Provencher M, Hoegg C. Vertical transmission of Citrobacter diversus from mother to infant. Pediatr Infect Dis J 1988; 7: 293-294.

8. Graham DR, Anderson RL, Ariel FE et al. Epidemic nosocomial meningitis due to Citrobacter diversus in neonates. J Infect Dis 1981 ; 144 : 203-209.

9. Parry MF, Hutchinson RN, Brown NA, Wu C-H, Estreller L. Gram-negative sepsis in neonates: a nursery outbreak due to hand carriage of Citrobacter diversus. Pediatrics 1980; 65: $1105-1109$.

10. Williams WW, Mariano J, Spurrier M et al. Nosocomial meningitis due to Citrobacter diversus in neonates: new aspects of epidemiology. I Infect Dis 1984; 150: 229-235.

11. Morris JG, Lin F-YC, Morrison CB et al. Molecular epidemiology of neonatal meningitis due to Citrobacter diversus: a study of isolates from hospitals in Maryland. $J$ Infect Dis $1986 ; 154: 409-414$

12. Ribeiro DC, Davis P, Jones DM. Citrobacter koseri meningitis in a special care baby unit. J Clin Pathol 1976; 29 : 1094 1096.

13. Kline MW, Mason EO, Kaplan SL. Characterization of Citrobacter diversus strains causing neonatal meningitis. $J$ Infect Dis 1988; 157: 101-105.

14. Li J, Musser JM, Beltran P, Kline MW, Selander RK. Genotypic hererogeneity of Citrobacter diversus expressing a 32-kilodalton outer membrane protein associated with neonatal meningitis. J Clin Microbiol 1990; 28: 1760-1765.

15. Richard C, Brisou B, Lioult J. Étude taxonomique de (Levinea), nouveau genre de la famille des entérobactéries. Ann Inst Pasteur 1972; 122: 1137-1146.

16. Maggs AF, Pennington TH. Temporal study of staphylococcal species on the skin of human subjects in isolation and clonal analysis of Staphylococcus capitis by sodium dodecyl sulfate-polyacrylamide gel electrophoresis. J Clin Microbiol $1989 ; 27: 2627-2632$.

17. Bjorvatn B, Lund V, Kristiansen B-E, Korsnes L, Spanne O, Lindqvist B. Applications of restriction endonuclease fingerprinting of chromosomal DNA of Neisseria meningitidis. J Clin Microbiol 1984; 19: 763-765.

18. Morris JG, Tall BD, Kotloff KL, Sechter I. Carriage of Citrobacter diversus among young children in Baltimore Pediatr Infect Dis J 1988; 7: 294-296.

19. Kline MW, Kaplan SL, Hawkins EP, Mason EO. Pathogenesis of brain abscess formation in an infant rat model of Citrobacter diversus bacteremia and meningitis. I Infect Dis $1988 ; 157: 106-112$.

20. Kline MW, Mason EO, Kaplan SL. Epidemiologic marker system for Citrobacter diversus using outer membrane profiles. J Clin Microbiol 1989; 27 : 1793-1796.

21. Kline MW. Citrobacter meningitis and brain abscess in infancy. Epidemiology, pathogenesis, and treatment. $J$ Pediatr $1988 ; 113 ; 430-434$ 